\title{
Functional properties of a chitinase promoter from cab- bage (Brassica oleracea var. capitata)
}

\author{
TANG Guo Qing*, Yong Yan BAI, Shi Wei LOO \\ Shanghai Institute of Plant Physiology, Chinese Academy \\ of Sciences, 300 Fenglin Rd, Shanghai 200032, China.
}

\section{ABSTRACT}

The 5'-region of the chitinase gene cabch29, derived from Brassica oleracea var. capitata, has been sequenced and analyzed for cis-acting elements important in controlling gene expression in transgenic tobacco plants. Different 5 '-deletion fragments were linked to reporter gene $\beta$-glucuronidase (GUS) as translational fusions, and the expression of these chimeric genes was analyzed in vegetative organs and tissues. Sequences up to -651 showed some basal GUS activity with nearly equal levels in wounded and intact tissues. The addition of further upstream sequences (-651 to -1284) enhanced expression level, and the expression driven by this fragment was inducible by a factor of two to three-fold by wounding. Histochemical analysis of different tissue from transgenic plants that contain cabch29 promoter-GUS fusion gene demonstrated woundinducible and tissue-specific cabch29 promoter activity in plants containing the 1308 base pair fragment. The location of GUS activity appears to be cell-specific, being highest in vascular cells and epidermal cells of stem, leaf and roots. Meanwhile, the temporal and spatial expression of cabch29-GUS fusion gene has been investigated. Among the different vegetative organs, a high level of GUS activity was observed in stem and a moderate one in roots; whereas, wounding stress led to a high level of GUS in stem and moderate one in leaf.

Key words: Cabbage chitinase gene, promoter, ciselement, wound-response. 
Functional properties of a cabbage chitinase promoter

\section{INTRODUCTION}

During fungal attack or other stress, plants are induced to express a number of polypeptides that function either passively or actively to combat infection by the pathogenic organism and recover from injury. A part of these induced proteins, such as chitinase and $\beta-1,3$-glucanase, which are lytic enzymes that catalyze respectively the hydrolysis of chitin and $\beta$-1,3-glucan components of the fungal cell wall, formed the unique defense system.

In dicotyledons, extensive studies have shown that microbial attack or other stress induces the transcription of various defense genes encoding above proteins, and their mRNA and enzyme levels are highly regulated during plant orgnaogenesis and in response to environment cues[1].

It is always attractive to understand the mechanism(s) by which plants perceive and respond to pathogenic attack and environmental stress, and to provide the basis for dissection of signal pathways for the induction of defense response by stress. And as part of a massive switch in the overall pattern of gene expression, the functional properties of the promoters of several defense genes have been characterized[2-7].

Recently, we have cloned chitinase cabch29 gene from cabbage (Brassica oleracea var. capitata). Sequence analysis revealed that its structure has some unique features different from other classes of plant chitinase[8]. Toward an approach of its regulatory mechanism, we have also studied the regulation of promoter region by deletion analysis which indicated that cabch29 gene expression is temporal and spatial in character. For intact plant, high expression level of cabch29-promoter $\beta$-glucuronidase(GUS) fusion gene was observed in stem and moderate in root; whereas, upon wounding expression level was high in stem and moderate in leaf. More detailed 5'deletion analysis showed that the proximal region of the promoter to -651 is sufficient to establish the full tissue-specific pattern of expression; while the distal region from - 651 to -1284 has some enhancer-like properties and is responsive to environmental stimuli such as wounding. Positive and negative elements are located somewhere between -1284 and -1007 , between -1007 and -966 , and between -966 and -651.

\section{MATERIALS AND METHODS}

\section{Construction of promoter deletion mutants of cabch29-GUS fusion gene}

As shown in Fig 1, based on the results of transient assay, we have isolated a cabch29-GUS fusion gene clone p13-5, containing 1308 bp 5'upstream region from cabch29, $2.2 \mathrm{~kb}$ GUS fragment and vector pBluescriptIIKS(+). The unidirectional 5'-deletion mutants of the cabch29-GUS fusion gene were generated through treatment with ExoIII and S1[9]. These individual mutants were digested with KpnI, modified by T4 DNA polymerase and then digested with EcoRI. Meanwhile, plasmid pBI101.1 was cut by the same restriction enzymes to remove GUS fragment and then performed ligation. These working constructs for functional analysis included intact promoter' (-1284, pTGQ1), and deletion mutants such as -1007(pTGQ2), -966(pTGQ3) and -651(pTGQ4). 


\section{Tobacco transformation}

Each mutant was directly transformed into Agrobacterium tumefaciens LBA4404 and transgenic tobacco plants generated by leaf disco method. Transformed plants were selected on Murashige and Skoog medium supplemented with $1 \mathrm{mg} / \mathrm{L} 6 \mathrm{BA}, 300 \mu \mathrm{g} / \mathrm{ml}$ kanamycin and $500 \mu \mathrm{g} / \mathrm{ml}$ carbenicillin or cefatoxin, and grown at $25^{\circ} \mathrm{C}$ under a $16 \mathrm{~h}$ light $1800 \mathrm{lux} / 8 \mathrm{~h}$ dark cycle.

\section{Wound induction}

Discos (about $6 \mathrm{~mm}$ in diameter) excised from fully expanded leaves were incubated in a wet capsules at $25^{\circ} \mathrm{C}$ in the dark for $24 \mathrm{~h}$, then they were stained histochemically in X-Gluc solution or snap frozen in liquid nitrogen and stored at $-70^{\circ} \mathrm{C}$.

\section{GUS assay}

GUS assays were performed on explants of primary transformants. Root, stem and leaf tissues were collected from $10 \mathrm{~cm}$ tall plantlets. GUS activity was assayed in tissue extracts by fluorimetric determination of the production of 4-methyl-lumbelliferone from the corresponding $\beta$-glucuronide[11, 12]. Protein was determined by the method of Bradford[13] and GUS activity was expressed as pmol of product per min per $\mathrm{mg}$ of protein discounted by background level. Histochemical localization of GUS activity in situ was performed with the chromogenic substrate 5-bromo-4-chloro-3-indolyl- $\beta$-D-glucuronide (X-Gluc). Stem and petiole sections were cut by hand, roots were directly incubated in X-Gluc solution. After inocubation for $2 \mathrm{~h}$, chlorophyll was removed by immersion of tissue samples in $70 \%$ ethanol prior to examination using a Nikon microscope.

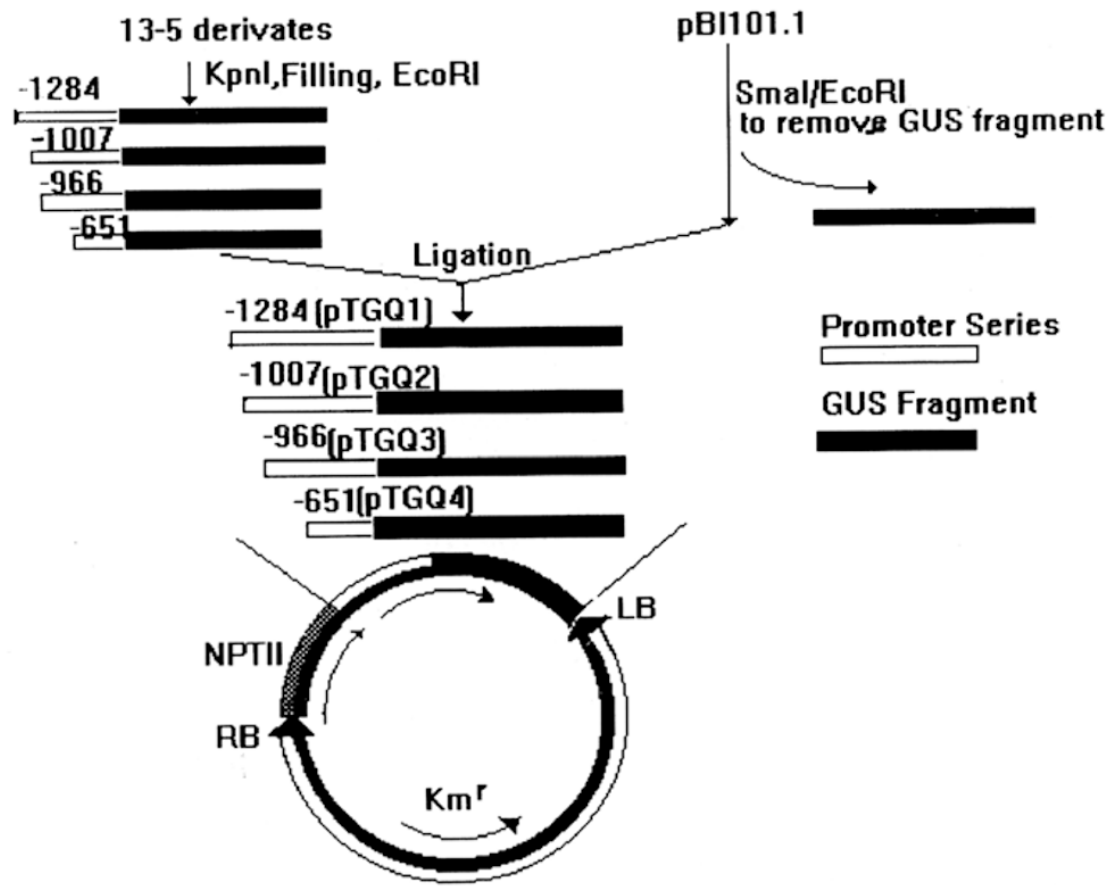

Fig 1. Construction of plsmids. Schematic diagram illustrating the size and extent of different 5 '-deletion mutants of cabch29 promoter-GUS fusion gene used for expression studies in transgenic plants. The hollow box represents the various promoter region and the solid box GUS code region. 
Functional properties of a cabbage chitinase promoter

\section{RESULTS}

\section{Organ, tissue-specific expression and wound induction}

It has been inferred that plant chitinase plays an important role in normal development although the substrate of chitinase doesn't exist in plant. Now our results revealed that the cabch29 promoter-GUS fusion gene was also expressed in various vegetative organs. Thus, high GUS level was observed in stem and a moderate one in root, as compared with the relatively weak expression in leaf. Although there was, as expected, some variation among the independent transformats in absolute

Fig 2. Normal (black) and woundinducible (shaded) expressions of cabch 29 promoter-GUS fusion gene in vegetative organs of transgenic tobacco plantlets. GUS gene was under the control the intact cabch29 promoter 5 'end at -1284 . GUS activity was represented as pmole per min per mg.

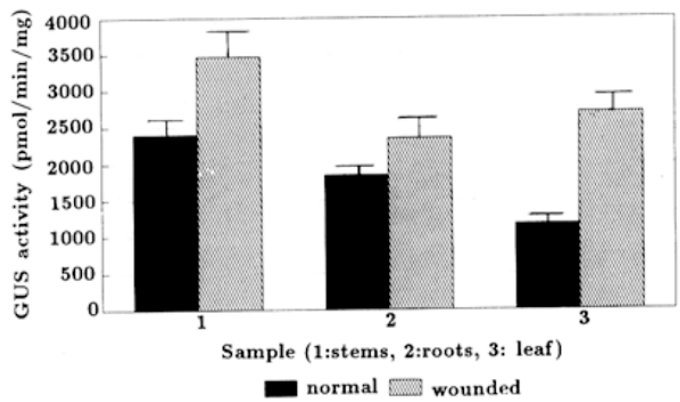

levels of expression, same overall pattern of normal GUS activity was still observed in each case: stems > roots > leaf (Fig 2). Upon excision wounding, the pattern of wound-inducible cabch29 promoter-GUS fusion gene expression changed into an order of stems $>$ leaf > roots (Fig 2). Histochemical localization of GUS activity in stem, root and leaf confirmed the vascular tissue and epidermis distribution pattern of expression as shown in Fig 3, a-c.

The induction of the chitinase promoter was monitored during the course of wounding by staining excising leaf tissue with X-Gluc. In contrast to control condition, a more obvious thin light-blue line was apparent around the cut edge as a result of wounding (Fig 3, d). Thus, it may be concluded that the cabch29 chitinase promoter is probably activated during wounding, at least, at the site of wounding.

\section{Promoter deletion and wound induction}

Effect of 5'-deletions on organ-specific and tissue-specific expression

To localize cis-elements that specify the complex developmental regulation and stress induction of the cabch29 promoter, the expression of fusion genes with promoter 5'-deletion mutants from -1284 to -1007(pTGQ2), to -966(pTGQ3) and to -651(pTGQ4) (as shown in Fig 1) was analyzed. As shown in Fig 4, the levels of extractable GUS activity in leaf, stem, and root of plants harboring the cabch29-GUS fusion gene with intact promoter and the effects of consecutive 5' promoter deletions 

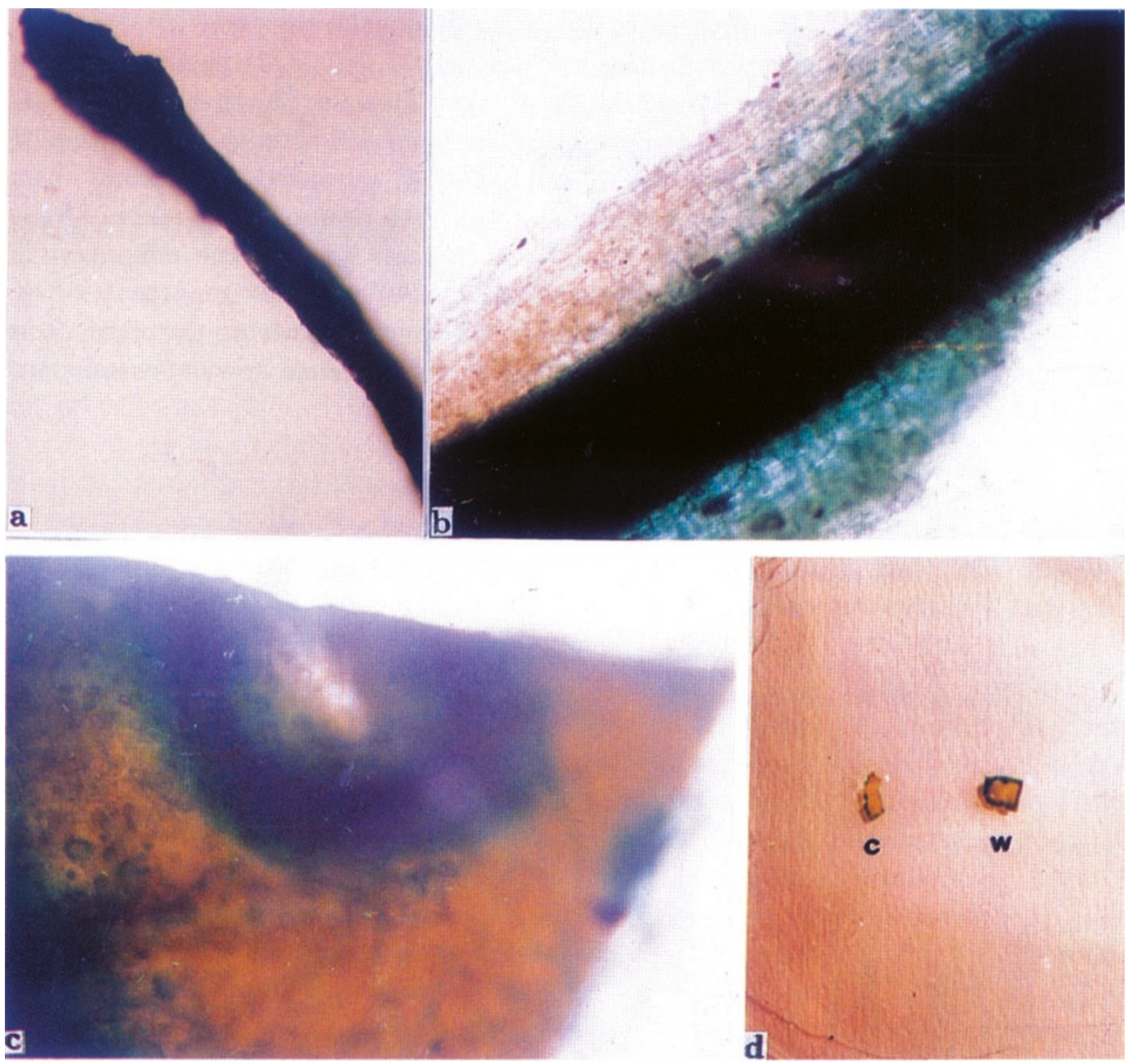

Fig 3. In situ demonstration of the presence of GUS activity in transgenic plantlets containing GUS gene under the control of intact cabch29 promoter up to -1284.

a, root tip; b, stem; c, leaf; d, stress indution in leaf disco: (w) wound-induced leaf disco $24 \mathrm{~h}$ after excision, (c)disco immediately after excision.

in plants transformed with respective constructs were compared.

Deletion of the promoter from nucleotide-1284 to -1007(pTGQ2) resulted in a decrease to $40 \%$ of GUS activity in leaf with intact or full-length promoter. Further deletion of the promoter to -966(pTGQ3) led to a stepwise decrease to about $27 \%$ of the activity with intact promoter.

Deletion of the promoter from -1284 to-1007(pTGQ2) resulted in a decrease to $68 \%$ of GUS activity extractable from root. Likewise, further deletions of the 
promoter to -966 (pTGQ3) and to -651(pTGQ4) led to stepwise decrease to about $44 \%$ and $27 \%$, respectively, of the activity with full-length promoter.

Meanwhile, deletion from nucleotide -1284 to -1007 (pTGQ2) resulted in a decrease to $40 \%$ of GUS activity extractible from stem. However, further deletion of to -966 (pTGQ3) caused a slight increase to about 54\% of GUS activity with full-length promoter, but a still further deletion to -651 (pTGQ4) again led to a second sharp decrease to about $22 \%$ of GUS activity with full-length promoter.

Thus, the above data suggested that there appears to be some enhancer-like element(s) located between nucleotides -1284 and -1007 which is important for expression of the fusion gene in vegetative organs. Furthermore, within the region from -1007 to -966 , it probably contains a negative-element for stem-specific expression.

Fig 4. Differential gene expression of 5 '-deletion mutants of cabch29 promoter-GUS fusion gene in various vegetative organs of transgenic tobacco plant.
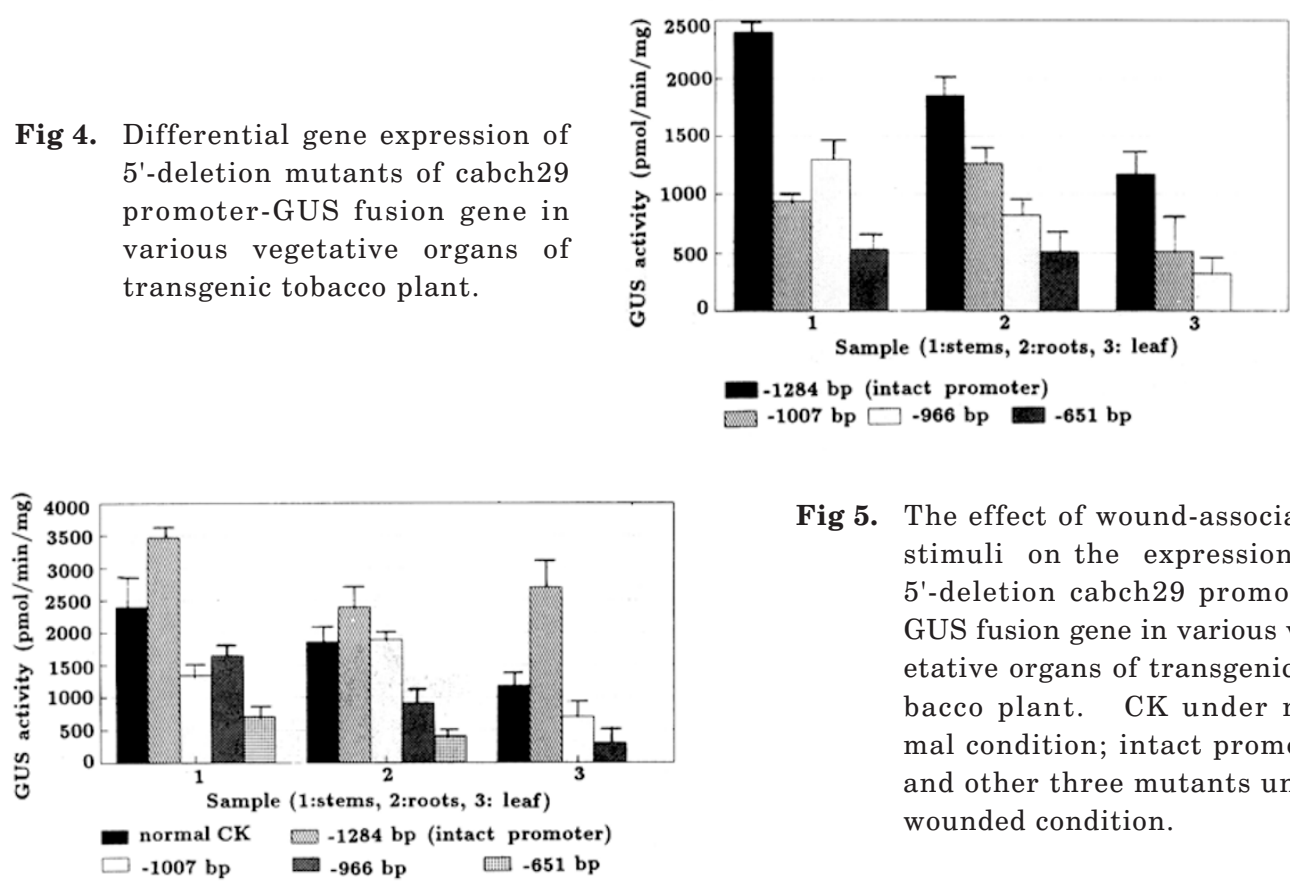

Fig 5. The effect of wound-associated stimuli on the expression of 5 '-deletion cabch29 promoterGUS fusion gene in various vegetative organs of transgenic tobacco plant. CK under normal condition; intact promoter and other three mutants under wounded condition.

Effect of 5'-deletions on expression induction by wound-associated stimuli

Vegetative organs from transformants harboring different deletion constructs were harvested for the quantitative measure of chitinase promoter activity under wound condition. As shown in Fig 5, the overall pattern of cabch29-GUS fusion gene expression with intact promoter appeared to be in the order: stem $>$ leaf $>$ root which was similar to the expression under wounded condition given in Fig 2. However, when the actual ratio of the net increase of induced activity was considered, relative to the value of $\mathrm{CK}$, the order became leaf $>$ stem $>$ root, due to the low GUS activity in normal leaf (Fig 5). 
In the case of promoter delection mutants, the effect of wounding on fusion gene expression in different vagetative organs, as shown in Fig 5 followed the general tendency of the stepwise decrease of GUS activity with the increasing deletion of nucleotides in promoter region given in Fig 4. This was also true with the slight increase of GUS activity in stem of mutant -966(pTGQ3).

\section{DISCUSSION}

An important component of the plant defense system is the induction of a number of pathogenesis-related proteins. One of these is the enzyme chitinase[14-17], which has been shown by in vitro experiments to be able to hydrolyze partially isolated fungal cell walls[18] and inhibit the growth of certain phytopathogenic fungi[19, 20]. Furthermore, plant chitinase gene expression is inducible by ethylene, oligosaccharide elicitors, wounding and pathogen attack[4].

We are interested in understanding the mechanism(s) by which plants perceive and respond to wounding. In this regard, we have studied some promoter property of chitinase cabch29 gene from Brassica oleracea var. capitata. A functional analysis of the cabch29 5' upstream sequence was carried out in transgenic tobacco plants. The sequence of the tested cabch29 full-length promoter comprised $1308 \mathrm{bp}$,including 24 bp putative translated region. Several 5'-deletion mutants were fused to GUS and tested in transgenic tobacco plants. A region responsible for wound inducibility and expression enhancement could be identified. Sequences up to -651 , including TATA and CAAT box, showed basal expression level in different vegetative organs that could not be further stimulated by wounding. The addition of upstream sequence up to -966 demonstrated some increase of GUS expression in certain wounded organs than in corresponding nonwounded ones. The further addition of $319 \mathrm{bp}$ (from -966 to -1284) enhanced the overall expression to a factor of 1.3 to 2.3 folds. Just as promoters of bean and rice chitinase genes[5, 21], two regions necessary for optimal gene expression have been identified in cabch29 gene: a quantitative region required for maximal gene expression and a region required for induced gene expression by stimulus; but one thing that had to be noted is the possible presence of a negative element specific to stem, in the region between -1007 and -966. Computer-aided search has found some wound-response cis-elements and tissue-specific elements in that region, but whether these elements actually play a role in wound inducibility and tissue-specific expression will have to be proven.

The histochemical analysis of transgenic tobacco plants carrying cabch29-GUS deletion mutants confirmed the results obtained from GUS activity measurements. Leaf, stem and root of transgenic plants harboring the full-length promoter (-1284) and some of mutants $(-1007,-966)$ showed high wound-inducible GUS activity. In X-Gluc-stained cross-sections of these tissues, their GUS activity could be specifically located in the vascular and epidermal tissue of these vegetative organs. The strong and specific cabch29 promoter- GUS fusion gene expression in epidermis 
ceils and vascular systems of leaf, stem and root tips suggested the possibility that cabch29 gene product might be involved in the defense of pathogens that invade the plant mainly through the epidermis, vascular tissue and root tips, and that wound-signaling is dependent on vascular tissue transport.

Antoniw and White (1986) have analyzed the distribution of the pathogenesisrelated protein PRla in local lesions of tobacco infected with TMV[22]. PRla protein level was found to be highest in the region immediately surrounding the viral lesion, while only low level was present in the lesion itself. Ohshima et al. (1990) have studied the induction of PRla promoter in transgenic tobacco plants. GUS enzyme activity was found to be increased by the treatment with salicylic acid, by wounding, and by TMV-associated local lesion formation[23]. Histochemical staining of TMV-infected tissues showed a localized induction of GUS activity which was consistent with the distribution of endogenous PRla protein found by Antoniw and White[22]. Failure to observe GUS activity within the TMV lesions was attributed to the degradation of the protein in the necrotic cells. Upon wounding cabch29 expression occurred in the region immediately surrounding the wounded lesion.

Mechanism of signal transduction includes a complicated series of molecular, biochemical and physiological steps, and it is programmed to take place responsively. The localized induction of the cabbage chitinase promoter suggested that the signal that mediates promoter activation was concentrated at the site of wounding in the same manner as in bean, poplar and rice. In the case of infection by $B$. cinerea (a kind of fungi), signal intensity decreased sharply with increasing distance from the site of infection. As in poplar, transgene activation in remote leaf (1.7-fold) was much less than that in the wounded leaf (10.8-fold)[24]. Some wound inducible genes have systemic inducibility. A localized induction of chitinase enzyme activity has been reported for infection of cucumber plants by Colletotrichum lagenarium and tobacco necrosis virus[25]. With both treatments, a weaker systemic induction of chitinase activity was apparent at distance removed from the inoculation site. Chitinase activity has also been found to be locally and systemically induced in melon plants during fungal infection or upon treatment with elicitor[26]. Conversely, Pearce et a1.[27] showed that systemic wound-inducible expression of a tobacco proteinase inhibitor increased more in the unwounded remote leaf of a wounded plant than in the wounded leaf itself. Thus, it seems that various wound-inducible genes may have different pathway of signal transduction themseles. At least in plant chitinase, decreased induction of GUS enzyme activity at distances far removed from the injury site may reflect the presence of the signal gradient in transgenic tobacco plants during wounding.

It is generally agreed that the interaction between cis-elements and trans-factors mediates gene expression. More detailed computer-aided nucleotide sequence comparison has identified several cis-element sequences which are conserved among the promoters of several plant defense genes and some cis-element sequences related to tissue and cell-specific expression. In the present work some putative 
wound-response elements including AGC box-like sequences[28], TCA motif-like sequences[28], carrot extensin gene wound-response elements (AT- rich motif, TTTTTTT, TGACGT) [29], constitutive PAL footprint and elicitor-inducible PAL footprint [31], and proteinase inhibitor II footprint[31] have been found in cabch29 promoter. Some cis-elements related to organ and tissue-specific expression such as GATA motif-like sequence, ASF-1 binding site-like elements also existed in 5' upstream region. Meanwhile, some basic transcriptional regulatory cis-elements including $\mathrm{G}$ box-like and GC box-like elements are located in this region. It will be attractive to identify and characterize these cis-elements further in relation to their possible role played in signal transduction pathway and gene expression upon various stress environment.

\section{ACKNOWLEDGEMENTS}

We thank Mr. WU Shao Be and Mr. WU Duen Su, Shanghai Institute of Plant Physiology, for their help in detecting GUS activity and taking photography.

\section{REFERENCES}

[1] Dixon RA, Lamb CJ. Molecular communication in plant: microbial pathogen interactions. Ann Rev Plant Physiol Plant Mol Biol 1990; 4:339-67.

[2] Cramer CL, Ryder TB, Bell JN, Lamb CJ. Rapid switch of plant gene expression by fungal elicitor. Science 1985; 227:1240-3.

[3] Dixon RA, Harrison MJ. Activation, structure, and organization of genes involved in microbial defense in plants. Adv Genet 1990; 28:165-234.

[4] Roby D, Broglie K, Cressman R, Biddle P, Chet L, Broglie R. Activation of a bean chitinase promoter in transgenic tobacco plant by phytopathogenic fungi. The Plant Cell 1990; 2:9991007.

[5] Zhu Q, Doerner PW, Lamb CJ. Stress induction and developmental regulation of a rice chitinase promoter in transgenic tobacco. The Plant Journal 1993; 2:203-12.

[6] Clarke HRG, Davis JM, Sibylle M, Wilbert, Harvey D, Bradshaaw Jr, Gordon MP. Woundinduced and developmental activation of a poplar tree chitinase gene promoter in transgenic tobacco. Plant Mol Biol 1994; 25:799-815.

[7] Logemann J, Lipphardt S, Lorz H, Hauser I, Willmitzer L, Schell J. 1989 5'-upstream sequences from the wun 1 gene are responsible for gene activation by wounding in transgenic plants. The Plant Cell 1989; 1:151-8.

[8] Tang GQ, Bai YY, Loo Sw. Molecular cloning and primary sequence analysis of a gene encoding a putative chitinase gene in Brassica oleracea var. capitata. Cell Research 1996; 6:65-73.

[9] Henikoff S. Unidirectional digestion with exonuclease III creates targeted break points for DNA sequencing. Gene 1984; 28:351-9.

[10] Rogers SG, Horsch RB, Fraleg RT. Gene transfer in plants: production of transformed plant using Ti-plasmid vector. Methods Enzymol 1986; 118:627-40.

[11] Jefferson RA. Assaying chimeric genes in plants: the GUS gene fusion system. Plant Mol Biol Rep 1987; 5:287-305.

[12] Jefferson RA, Kavangh TA, Bevan MW. GUS fusions: $\beta$ - glucuronidase as a sensitive and versatile gene fusion marker in higher plants. EMBO J 1987; 6:3901-7.

[13] Bradford MM. A rapid and sensitive method for the quantitation of microgram quantities of protein utilizing the principle of protein-dye binding. Anal Biochem 1976; 72:248-54. 


\section{Functional properties of a cabbage chitinase promoter}

[14] Legrand M, Kauffman S, Geoffroy P, Fritig B. Biological function of pathogenesis-related proteins: Four tobacco pathogenesis-related proteins are chitinase. Proc Natl Acad Sci USA 1987; 84:6750-4.

[15] Kombrink E, Schroder M, Hahlbrock K. Several pathogenesis-related proteins are 1, 3 - $\beta$-glucanase and chitinase. Proc Natl Acad Sci USA 1988; 85:782-6.

[16] Awade A, DeTapia M, Didierjean L, Burkard G. Biological function of bean pathogenesis-related (PR3 and PR4) proteins. Plant Science 1989; 63:121-30.

[17] Mauch F, Hadwiger LA, Boller T. Antifungal hydrolases in pea tissue. 1. Purification and characterization of two chitinase and 1,3 - $\beta$-glucanase differentially regulated during development and in response to fungal infection. Plant physiol 1988; 87:325-33.

[18] Boller T, Gehri A, Mauch F, Vogeli U. Chitinase in bean leaves: induction by ethylene, purification, properties and possible function. Planta 1983; 157:22-31.

[19] Schlumbaum A, Mauch F, Vogel U, and Boller T. Plant chitinases are potent inhibitors of fungal growth. Nature 1986; 324:365-7.

[20] Mauch F, Mauch-Mani B, Boller T. Antifungal hydrolase in pea tissue.ll. Inhibitor of fungal growth by combinations of chitinase and $\beta-1,3$-glucanase. Plant Physiol 1988; 88:936-42.

[21] Broglie KE, Gaynor JJ, Broglie RM. Ethylene-regulated gene expression: molecular cloning of the genes encoding an endochitinase from Phaseolus vulgaris. Proc Natl Acad Sci USA 1986; 83:6820-4.

[22] Antoniw JF, White RF. Changes with time in the distribution of virus and PR protein around single local lesions of TMV infected tobacco. Plant Mol Biol 1986; 6:145-9

[23] Ohshima M, Hoth H, Matsuooka M, Murakami T, and Ohashi Y. Analysis of stress-induced or salicylic acid-induced expression of the pathogenesis-related 1a protein in transgenic tobacco. The Plant Cell 1990; 2:95-106

[24] Howard RG, Clarke John M, Davis Sibylle M, Wilbert Harvey D, Bradshow Jr, Gordon MP. (1994) Wound-induced and developmental activation of a poplar tree chitinase gene promoter in transgenic tobacco. Plant Mol Biol 1994; 25:799-815

[25] Metraux JP, Boller T. Local and systemic induction of chitinase in cucumber plants in response to viral, bacterrial, and fungal infections. Physiol Mol Plant Pathol 1986; 28:161-9.

[26] Roby D, Toppan A, Esquerre-Tugaye MT. Systemic induction of chitinase activity and resistance in melon plants upon fungal infection or elicitor treatment. Physiol Mol Plant Pathol 1988; 33:409-17

[27] Pearce G, Johnson S, Ryan CA. Purification and characterization from tobacco (Nicotiana tabacum) leaves of six small, wound-inducible, proteinase isoinhibitors of the potato inhibitor 11 family. Plant Physiol 1993; 102:639-44.

[28] Hart CM, Nagy F, and Meins FJr. A 61 bp enhancer element of tobacco $\beta$-1, 3-glucanase B gene interacts with one or more regulated nuclear proteins. Plant Mol Bio 1993; 21:121-39.

[29] Holdsworht MJ, Laties GG. Site-specific binding of a nuclear factor to the carrot extensin gene is influenced by both ethylene and wounding. Planta 1989; 180:74-81.

[30] Lois R, Dietrich A, Hahlbrock K, Schulz W. A phenylalamine ammonia-lyase gene from parsley: structure, regulation and identification of elicitor and light response cia-acting elements. EMBO J 1989; 8:1641-8

[31] Palm CJ, Costa MA, An G, Ryan CA. Wound-inducible nuclear protein binds DNA fragment: that regulate a proteinase inhibitor 11 gene from potato. Proc Natl Acad Sci USA, 1990; 87:603-7.

Received 9-2-1996. Revised 14-6-1996. Accepted 17-6-1996. 